\author{
В.В. Фещенко \\ Институт языкознания РАН \\ (Россия, Москва) \\ takovich2@gmail.com
}

\title{
ЯЗЫКОВЫЕ АНОМАЛИИ РУССКОГО АВАНГАРДА В ФОКУСЕ ЛИНГВИСТИЧЕСКИХ ТЕОРИЙ*
}

Статья посвящена природе аномальных высказываний и текстов русского авангарда, а также их роли в формулировке лингвистических теорий начала XX века. Рассматриваются некоторые примеры из языковой практики авангардной литературы, которые своей аномальностью наталкивали лингвистов на новые осмысления природы языка. Дается определение аномального текста. Аномальный текст является результатом языкового эксперимента либо намеренного, либо ненамеренного. Анализируются примеры языковых аномалий в поэзии Р. Якобсона, И. Зданевича, И. Терентьева, В. Шершеневича в их проекции на языковедческие концепции И. Бодуэна де Куртенэ, Л. Щербы, Р. Якобсона. Делается вывод о том, что дискуссии лингвистов 1920-30-х гг. о роли правильных и неправильных высказываний в формировании языковых теорий совпадали и по времени, и содержательно с языковым экспериментом художественного толка, обнаруживая общие концептуальные ходы между наукой и искусством. За XX век языковой и литературный опыт проделал столь длительный и интригующий путь, что аномалии текста уже вряд ли можно рассматривать как болезнь языка, а скорее, как продуктивный способ языковой креативности, неологизации и авторефлексии.

Ключевые слова: языковые аномалии, аномальный текст, языковой эксперимент, теории языка, русский авангард.

При рассмотрении параметров авангардного текста в его неологических проявлениях существен вопрос о том, насколько аномальны все те явления, которые лингвист регистрирует в подобных текстах. Также существенен вопрос о влиянии языковых аномалий на сам процесс формирования лингвистической теории. Далее

* Исследование выполнено за счет гранта Российского научного фонда (проект № 19-1800040) в Институте языкознания РАН. 
мы рассмотрим некоторые примеры из языковой практики авангардной литературы, которые своей аномальностью наталкивали лингвистов на новые осмысления природы языка.

Начнем с того, как определяется языковая аномалия и как она проявляется в специфических текстах, в которых заметную роль играют аномальные механизмы текстопорождения и смыслообразования. Общее определение аномалии в лингвистике впервые было дано в 1970-е годы Ю. Д. Апресяном, понимавшим под ней «нарушение правила употребления какой-то языковой или текстовой единицы» [Апресян 1990: 50] и видевшим в ней «точки роста новых явлений». В дальнейшем такие лингвисты, как Н.Д. Арутюнова, Т. В. Булыгина, Б. А. Успенский и др., предложили классификации аномальных употреблений в языке [Арутюнова 1987; Булыгина, Шмелев 1997; Успенский 2007]. Следующим шагом в этом направлении стали работы по аномалиям в литературном тексте. И. М. Кобозева и И.Н. Лауфер [1990], а также Т. Б. Радбиль [2012] выделили разновидности аномальной вербализации текстовых категорий: связности, целостности, единства, субъективной модальности и др. Т.Б. Радбиль не только рассматривает все многообразие аномалий на различных уровнях языка конкретного автора (А. Платонова), но и ставит вопрос о специфических «текстовых аномалиях». На основе существующих трудов о языковых аномалиях можно сформулировать рабочее семиотическое определение аномального текста как любой написанной или произнесенной последовательности языковых знаков, демонстрирующих те или иные девиации от принятых в стандартном языке законов сочетаемости знаков и смыслов и, следовательно, отклоняющихся от принятых моделей коммуникации, понимания и интерпретациии в рамках данной знаковой системы. Аномальный текст является результатом языкового эксперимента, либо намеренного, либо ненамеренного (см. наше определение языкового эксперимента в [Фещенко 2009], а также о более широком периоде исследования аномальных текстов на протяжении всего XX в. в [Фещенко 2018: 274-294]).

Научная лингвистика, пожалуй, впервые сталкивается с проблемой аномалии языка в самом конце XIX в., на волне интереса различных наук к паранормальным явлениям. В частности, с вопросом осмысляемости бессмысленного текста сталкивается Ф. де Соссюр при анализе медиумистических текстов одной современной ему ясновидящей (см. об этом эпизоде нашу статью [Фещенко 2017]). Тексты Э. Смит нельзя назвать художественными, хотя большая доля вымысла имеет в них место.

С чисто художественными аномалиями языка столкнулся в своей научной практике другой, наряду с Соссюром, выдающийся родоначальник языкознания, И. Бодуэн де Куртенэ. В 1914 году он выступает в печати с критикой теории слова как такового, провозглашенной накануне футуристами Крученых, Хлебниковым и Бурлюком. Напомним, что одним из пунктов их манифеста «Пощечина общественному вкусу» было «увеличение словаря в его объеме произвольными и производными словами (Слово-новшество)» [Пощёчина 2000: 41]. Футуристами открыто заявляется бунт против «грамматических правил», отрицание правописания, 
уничтожение знаков препинания, декларация заумного языка. Как же реагирует на эти новшества теоретик языка? Бодуэн, выпустивший к тому моменту книгу «Об отношении русского письма к русскому языку», яростно сопротивляется возможности составления слов из произвольного набора «букв» и «звуков». Такие сочетания, как «го оснег кайт» и «еуы» расцениваются им как абсолютно аномальные, более того - невозможные в языке, даже в поэтическом. Невозможность таких «слов» в языке вызвана, согласно Бодуэну, тем базовым лингвистическим постулатом, что слова состоят не из звуков или букв, а из ассоциаций в человеческой психике представлений значений. А значит, эксперименты «Баячей» не относятся к области языка [Бодуэн де Куртенэ 1914б].

Это утверждение было, впрочем, вскоре оспорено учениками Бодуэна де Куртенэ - Р. Якобсоном и Г. Винокуром, показавшими, что аномальные языковые формы футуристов аномальны лишь по отношению к литературному языку, но не по отношению к создаваемому футуристами «новому языку». Тем не менее, экспериментально организованные тексты футуристов остаются аномальными по отношению к общелитературному языку, вскрывая между тем возможности, заложенные, но не реализованные в обыденно-речевом узусе. При этом лингвистическая теория начинает допускать творческое и преобразовательное отношение к языку. Если сомнения Соссюра в возможности абсолютно бессмысленного текста приводят его к коренной оппозиции звук - знак, то футуристический языковой эксперимент продвигает лингвистику еще дальше - к осознанию существования «словотворчества» и признания за заумным языком семиотического статуса наравне с языком обыденным и языком поэтическим.

Первые случаи употребления терминов «поэтический язык», «поэтическое высказывание» и «поэтическая функция» связаны с анализом Р. Якобсоном текстов Маринетти и Хлебникова. В противовес общественному и научному мнению своего времени, Якобсон выделяет творчество русского будетлянина как наиболее соответствующее языковой практике революционного времени. Аномальные с точки зрения литературной традиции и русской языковой диахронии стихи Хлебникова открывают исследователю языка новое видение своего предмета. Впервые лингвистика обращается не только к фактам живого языка в их синхронных изменениях, но и к языку актуальной литературы, к «поэтическому языку современности», по формулировке Якобсона. Авангард поэтический обусловливает научную революцию в языкознании. Так, именно в этих анализах рождается теория языковых функций (коммуникативная, эмоциональная, поэтическая и т.д.), которая станет парадигмообразующей в функционализме Пражской лингвистической школы. То, что в предыдущей парадигме (представленной Бодуэном де Куртенэ) считается внеязыковым (словоновшества футуристов) и вредным для языкового развития, признается в рамках парадигмы новой, наоборот, потенциально продуктивным для языкового творчества.

Бодуэн де Куртенэ сам был способен порождать аномальные сочетания слов, в его полемической статье против «зауми» приводится несколько примеров текстов на таком «заумном языке»: 
Караменота селулабиха

Кеременута шёвелесула

Тиутамкунита чорчорпелита

[Бодуэн де Куртенэ 1914а]

Однако бессмысленность таких сочетаний, напоминающих глоссопоэзис Элен Смит или глоссолалию русских сектантов, описанную у Д. Коновалова, В. Шкловского и Р. Якобсона, убеждает его в том, что язык не образуется из чистого звукосочетания. В отличие от Бодуэна, Шкловский, Якобсон и особенно поэты-футуристы видят в этих аномалиях эмбриональное состояние поэтического языка. К экспериментам в зауми прибегал, как известно, Р. Якобсон. То, что гораздо позднее, в 1970-е, он называл «грехами шестидесятилетней давности», в 1915-м служило моделью перехода от по-хлебниковски понимаемого «самовитого слова» к концептуальной формуле «поэтический язык как язык с установкой на выражение»:

\section{мзгльюбжвуо йихъяньдрью чтлэщк хн фя съп скыполза а Втаб-длкни тьяпра какайзчди евреец чернильница [Роман Якобсон 2012: 190]}

\section{В этом двустишии аномальны} не только грамматический строй и лексический состав, но и просодически-фонетическая система русской речи. Но такая аномальность породила в результате научный прорыв в лингвистической поэтике, сделав эту дисциплину важным направлением в особенности русского языкознания XX в. Заметим к слову, что Якобсон пробовал себя и в чем-то напоминающем асемическое письмо. В письме Хлебникову от 1914 г. приводится «образчик новой поэзии», составленный из «сплётов букв», напоминающих музыкальные аккорды [там же: вкладка] (илл. 1).

Якобсон-будетлянин тут же в письме признается в том, что такие экспериментальные опыты трамплин для новых идей в искусстве: «Далее, эти сплёты не могут быть вполне приемлемы физически,

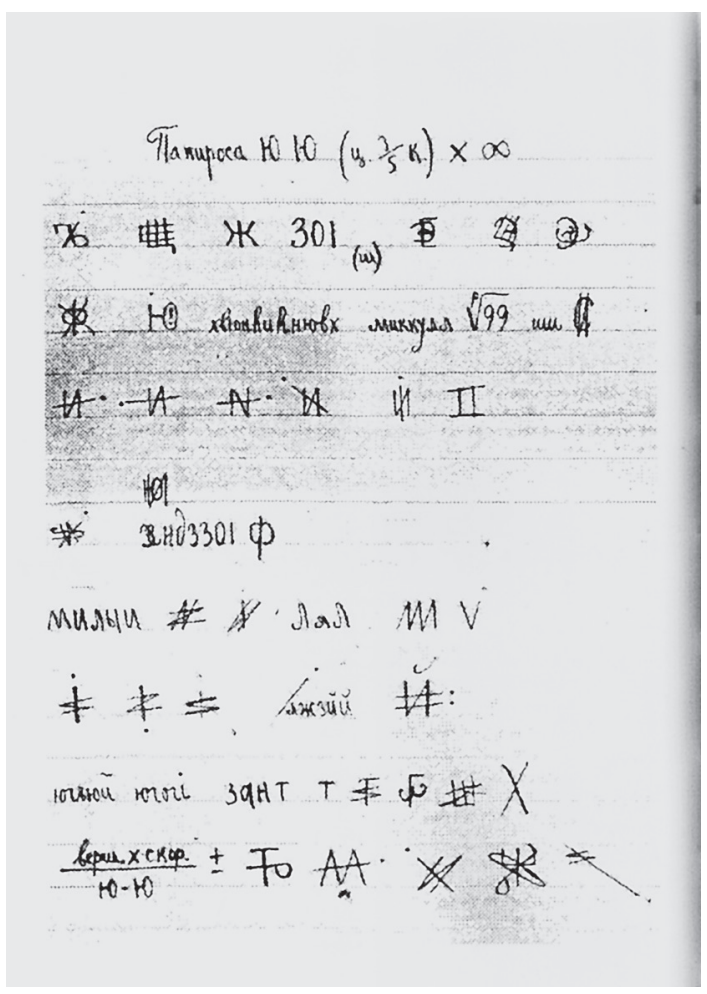

Илл. 1. Р. Якобсон. Образчик новой поэтической письменности из письма В. Хлебникову 1914 г. 
хазянн

гражани пот действа янко круль ал банскай знамишктава албанскава паә та 6рбр сталmа биржсофки пасвичена е ольги ляшковай здесь ни зпают а лбанскава изыха и бискровнае убий ства дает действа па ниволи бис пири вода так как албанскай нақк с ру ским идет ат ывоннава вы наблюдет н слана схожыи с рускими как та 己 сел балван галоша и таму падобнае на патаму шта слава албанскии смь сл ых ни рускай как та асел значит ( па нуже смктела ни приважсу ) и т аму падобнае пачнму ни смучдйтись помнити шта вот набк албанскай деи

янко ано в брноках с чюжсова плнч я абута новым времиним квдсь пренкбибдада

Илл. 2. И. Зданевич. Страница из пьесы «Янко крУль албАнскай» но доля неприемлемости - необходимая предпосылка нового искусства» [там же: 115]. Учитывая дальнейший вклад Якобсона в теорию знаковых систем, эти скромные опыты послужили «своей неприемлемостью» (т.е. аномальностью) предпосылкой и для новой науки - семиотики.

Другой русский футурист И. Зданевич пошел еще дальше в создании аномальных текстов на «заумном языке». Так, в одной из его «заумных дра» мы как будто бы наблюдаем речь, выбивающуюся из всех возможных законов языкового согласования [Зданевич 2008: 481] (илл. 2).

Мы вряд ли можем перевести этот текст на обычный семантический язык, однако, пристальный анализ может распознать в нем некий набор аномальных структур, благодаря чему этот текст остает-

ся текстом. Исследования литературоведов показали, что данные тексты при всей своей заумности кодируют весьма сложное содержание. И в этом, кстати, их отличие от на поверхности схожих явлений в современном языке интернета. Если «олбанский» язык интернета аномален только по ограниченному набору параметров (собственно, нарушение нескольких фонологических законов написания слов), то «заумный язык» Зданевича носит системный характер отклонений от языковых стандартов, затрагивая практически все семиотические параметры языковой системы - от фонологического и алфавитного до связности и непротиворечивости текста.

Кажется, именно такие эксперименты на разных уровнях языка сподвигли другого известного русского лингвиста Л. Щербу к синтаксическим и морфологическим опытам создания искусственных фраз. Своим знаменитым примером «Глокая куздра штеко будланула бокра и курдячит бокренка» Щерба стремился доказать тот факт, что даже при аномальной структуре на одном уровне языка (лексическом) высказывание может оставаться в рамках языка на другом уровне (грамматическом). При этом виртуозность созданного таким образом экспериментального текста сделала его поистине «звездным» в русской и зарубежной лингвистической литературе. Ф.Н. Двинятин даже предложил рассматривать его как поэтическое произведение, сходное с заумными текстами русских будетлян, а его автора - как 
участника рождения новой русской поэтики и поэтической практики [Двинятин 2003]. Для самого Щербы этот пример подчеркивал значимость лингвистического эксперимента и «отрицательного языкового материала» не только в обучении языку, но и в понимании сущности языковых явлений. В частности, этой фразой иллюстрировался важный тезис о том, что в сознании говорящего всегда присутствуют абстрактные грамматические структуры, подчас даже не нуждающиеся в лексически нормальном наполнении.

Примеры подобных упражнений Щерба при желании мог бы почерпнуть из существующей поэзии футуристов, например, из стихотворения И. Терентьева «Серенький козлик» 1918 г.:

\author{
Моснял мазами сено \\ Кутка неизверная \\ Тена фразам исчерна \\ Нерно прокатом \\ Окатом высокотом \\ Вуста уста стали \\ Сихи мелбормхаули \\ Мотма борма смений \\ Выборма вылисма вылотма \\ Выбормотался гений \\ Вот как. \\ [Игорь Терентьев 2012: 96]
}

Не исключено, что именно такие стихи могли вдохновить русского лингвиста на его лексико-грамматический эксперимент. Обратная процедура - coхранение лексической нормы в синтаксически аномальном сочетании проделывается В. Шершеневичем в стихотворении «Московская Верона»:

Лежать сугроб. Сидеть заборы.

Вскочить в огне твое окно.

И пусть я лишь шарманщик старый,

Шарманкой, сердие, пой во мне.

Полночь молчать. Хрипеть минуть.

Вдрызг пьяная тоска визжать.

Ты будь мой только подвиг сотьй,

Который мне до звезд воспеть.

[Шершеневич 1996]

Аномальное высказывание о «глокой куздре» стоит, таким образом, рассматривать в ряду собственно поэтических экспериментов, сопутствовавших в 191020-е гг. становлению новых концепций языка. Для Щербы лингвистический 
эксперимент служил подспорьем в его теории «речевой деятельности» как баланса между «языковой системой» и «языковым материалом», что, в свою очередь, являлось развитием теории Ф. де Соссюра.

Итак, в данной статье мы остановились на одной из ключевых характеристик авангардного текста, сопрягающих его с лингвистическим поворотом в науке его аномальности, а также аномальности высказывания вообще и поэтического высказывания, в частности. Дискуссии лингвистов 1920-30-х гг. о роли правильных и неправильных высказываний в формировании языковых теорий совпадали и по времени, и содержательно с языковым экспериментом художественного толка, обнаруживая общие концептуальные ходы между наукой и искусством. На заре лингвистической науки языковые аномалии были признаны «патологией» языка. Об этом в медицинских терминах рассуждал еще в 1885 году И. Бодуэн де Куртенэ: «В области языкознания описание и объяснение обычных, нормальных языковых явлений соответствует физиологии, а описание и объяснение языковых аномалий — патологии» [Бодуэн де Куртенэ 1963: 142]. За ХХ век языковой и литературный опыт проделал столь длительный и интригующий путь, что аномалии текста уже вряд ли можно рассматривать как болезнь языка, а скорее, как продуктивный способ языковой креативности, неологизации и авторефлексии.

\section{Литература}

Апресян Ю.Д. Языковые аномалии: типы и функции // Res Philologica: Филологические исследования. Памяти академика Георгия Владимировича Степанова (1919-1986). М.; Л.: Наука, 1990.С. 50-71.

Арутюнова Н.Д. Аномалии и язык (к проблеме языковой «картины мира») // Вопросы языкознания. 1987. №3. С. 3-19.

Бодуэн де Куртенэ И. А. Слово и «слово» // День, №49, 1914а. Режим доступа: http://rozanova.net/second_page.pl?id=416\&catid=14

Бодуэн де Куртенэ И.А. К теории «слова как такового» и «буквы как таковой» // День, № 56, 19146 [Электронный pecypc]. URL: http://rozanova.net/second page.pl?id=415\&catid $=14$

Бодуэн де Куртенэ И. А. Из патологии и эмбриологии языка // Избранные труды по общему языкознанию. Т. 1. М.: Издательство Академии наук СССР, 1963. C. $142-145$.

Бульгина Т.В., Шмелев А.Д. Языковая концептуализация мира (на материале русской грамматики). М.: Языки русской культуры, 1997. 557 с.

Двинятин Ф.Н. Заумный Щерба: к поэтике фразы про глокую куздру // Евразийское пространство: Звук, слово, образ. М.: Языки славянской культуры, 2003. С. 383-394.

Зданевич И. М. (Ильязд). Философия футуриста: Романы и заумные драмы. М.: Гилея, 2008. 840 с.

Игорь Терентьев. Левейший из левых. К 120-летию со дня рождения. Сборник материалов. М.: Государственный музей Маяковского, 2012. 249 с. 
Кобозева И. М., Лауфер Н. И. Языковые аномалии в прозе А. Платонова через призму процесса вербализации // Логический анализ языка: Противоречивость и аномальность текста: Сб. научн. трудов. М.: Наука, 1990. С. 194-224.

Пощёчина общественному вкусу // Русский футуризм: Теория. Практика. Критика. Воспоминания. М.: ИМЛИ РAH, Наследие, 2000 [Электронный ресурс]. URL: http://a-pesni.org/zona/avangard/manifesty.php

Радбиль Т.Б. Языковые аномалии в художественном тексте: Андрей Платонов и другие. М.: Флинта, 2012. 322 с.

Роман Якобсон. Будетлянин науки: Воспоминания, письма, статьи, стихи, проза. М.: Гилея, 2012. 306 с.

Успенский Б. А. Ego Loquens: Язык и коммуникационное пространство. М.: РГГУ, 2007. $320 \mathrm{c}$.

Фещенко В. В. Лаборатория логоса: Языковой эксперимент в авангардном творчестве. М.: Языки славянских культур, 2009. 390 с.

Фещенко В. В. Messages from a medium: Ф. де Соссюр, Т. Флурнуа и случай одной ясновидящей // Критика и семиотика. 2017. № 1. С. 109-123.

Фещенко В.В. Литературный авангард на лингвистических поворотах. СПб.: Издательство Евпропейского Университета в Сантк-Петербурге, 2018. 380 с.

Шершеневич В.Г. Листы имажиниста: Стихотворения. Поэмы. Теоретические работы. Ярославль: Верх.-Волж. кн. изд-во, 1996 [Электронный ресурс]. URL: http://az.lib.ru/s/shershenewich_w_g/text_1935_poe.shtml

\author{
V.V. Feshchenko \\ Institute of Linguistics of the Russian Academy of Sciences \\ (Russia Moscow) \\ takovich2@gmail.com
}

\title{
LANGUAGE ANOMALIES OF THE RUSSIAN AVANT-GARDE IN THE FOCUS OF LINGUISTIC THEORIES
}

The article discusses the nature of anomalous utterances and texts of the Russian avantgarde, as well as their role in the formulation of linguistic theories of the early twentieth century. It contains an analysis of some examples from language practices of avant-garde literature, which, due to their anomalous nature, pushed linguists to new interpretations of the nature of language. We formulate a definition of anomalous text. An anomalous text is the result of a linguistic experiment, either intentional or unintentional. The study analyzes examples of language anomalies in the poetry of R. Jakobson, I. Zdanevich, I. Terent'ev, V. Shershenevich in their projection on the linguistic concepts of I. Baudouin de Courtenay, L. Shcherba, R. Jakobson. Our conclusion is that the discussions by linguists of the 1920s-1930s of the role of correct and incorrect statements in the formation of linguistic theories coincided in time, and in essence, with artistic language experiments, revealing 
common conceptual moves between science and art. For the twentieth century, linguistic and literary experience has made such a long and intriguing path that the anomalies of the text can hardly be regarded as a disease of language, but rather as a productive way of linguistic creativity, neologization and self-reflexion.

Key words: language anomalies, anomalous text, language experiment, linguistic theory, Russian avant-garde.

\section{References}

Apresyan Yu. D. [Language anomalies: types and functions]. Res Philologica: Filologicheskie issledovaniya. Pamyati akademika Georgiya Vladimirovicha Stepanova (1919-1986). Moscow; Leningrad, Nauka Publ., 1990, pp. 50-71. (In Russ.).

Arutyunova N.D. [Anomalies and language (towards the problem of the language «world image»)]. Voprosy jazykoznanija, 1987, no. 3, pp. 3-19. (In Russ.).

Baudouin de Courtenay I. A. [Word and «word»]. Den', no. 49, 1914a. [In Russ.]. Available at: http://rozanova.net/second_page.pl?id=416\&catid=14

Baudouin de Courtenay I. A. [To the theory of «words as such» and «letters as such»]. Den', no. 56, 1914b. [In Russ.]. Available at: http://rozanova.net/second_page. pl?id=415\&catid $=14$

Baudouin de Courtenay I. A. [From pathology and embryology of language]. Izbrannye trudy po obshchemu yazykoznaniyu. Vol. 1. Moscow: Academy of Sciences of the USSR Publ., 1963, pp. 142-145.

Bulygina T.V., Shmelev A.D. Yazykovaya kontseptualizatsiya mira (na materiale russkoi grammatiki) [Language conceptualization of the world (on the basis of the Russian grammar)]. Moscow: Yazyki Russkoi Kul'tury Publ., 1997. 557 p.

Dvinyatin F. N. Transrational Shcherba: towards the poetics of glokaya kuzdra]. Evraziiskoe prostranstvo: Zvuk, slovo, obraz. Moscow: Yazyki Slavyanskoi Kul'tury Publ., 2003, pp. 383-394. (In Russ.).

Feshchenko V.V. Laboratoriya logosa: Yazykovoi eksperiment v avangardnom tvorchestve [Laboratory of the Logos: Language experiment in avant-garde art]. Moscow: Yazyki Slavyanskikh Kul'tur Publ., 2009. 390 p.

Feshchenko V.V. [Messages from a medium: F. de Saussure, T. Flournoy and a case of a clairvoyant]. Kritika i semiotika, no. 1, 2017, pp. 109-123. (In Russ.).

Feshchenko V. V. Literaturnyi avangard na lingvisticheskikh povorotakh [The linguistic turns of the literary avant-garde]. St. Petersburg.: European University in St. Petersburg Publ., 2018. 380 p.

Igor' Terent'ev. Leveishii iz levykh. K 120-letiyu so dnya rozhdeniya. Sbornik materialov [Igor' Terent'ev. The most left of the left. To the 120th anniversary of his birth. Collection of materials]. Moscow: State Mayakovsky Museum Publ., 2012. 249 p.

Kobozeva I. M., Laufer N. I. [Language anomalies in the prose of A. Platonov through the prism of the process of verbalization]. Logicheskii analiz yazyka: Protivorechivost' $i$ anomal'nost' teksta: Sb. nauchn. trudov [Logical analysis of language. A collection of research articles]. Moscow: Nauka Publ., 1990, pp. 194-224. (In Russ.). 
[A slap in the face of public taste]. Russkii futurizm: Teoriya. Praktika. Kritika. Vospominaniya [Russian Futurism. Theory. Practice. Criticism. Memories]. Moscow: Institute of the World Literature, Russian Academy of Sciences, Nasledie Publ., 2000. [In Russ.]. Available at: http://a-pesni.org/zona/avangard/manifesty.php

Radbil' T. B. Yazykovye anomalii v khudozhestvennom tekste: Andrei Platonov i drugie [Language anomalies in the literary text: Andrei Platonov and others]. Moscow: Flinta Publ., 2012. 322 p.

Roman Jakobson. Budetlyanin nauki: Vospominaniya, pis'ma, stat'i, stikhi, proza [Roman Jakobson. A futurian of the science: Memoirs, letters, articles, poems, prose]. Moscow: Hylaea Publ., 2012. 306 p.

Shershenevich V.G. Listy imazhinista: Stikhotvoreniya. Poemy. Teoreticheskie raboty [Sheets of the Imagist: Poems. Theoretical works]. Yaroslavl': Verkhnevolzhskoe knizhnoe izd-vo, 1996. Available at: http://az.lib.ru/s/shershenewich_w_g/text_1935_ poe.shtml.

Uspenskii B. A. Ego Loquens: Yazyk i kommunikatsionnoe prostranstvo [Ego loquens: Language and communication space]. Moscow: Russian State Univ. for the $\mathrm{Hu}-$ manities Publ., 2007. 320 p.

Zdanevich I. M. (Il'yazd). Filosofiya futurista: Romany i zaumnye dramy [Philosophy of the Futurist: Novels and transrational dramas]. Moscow: Hylaea, 2008. 840 p. 